\title{
Effects of relative submergence and bed slope on sediment incipient motion under decelerating flows
}

\author{
Ramin Bolhassani ${ }^{1}$, Hossein Afzalimehr ${ }^{1 *}$, Subhasish Dey ${ }^{2}$ \\ ${ }^{1}$ Department of Water Engineering, Isfahan University of Technology, Boulevard of University, Isfahan, Iran. \\ ${ }^{2}$ Department of Civil Engineering, Indian Institute of Technology, Kharagpur 721302, West Bengal, India. \\ * Corresponding author. E-mail: hafzali4@gmail.com
}

\begin{abstract}
This paper presents the results of an experimental study to quantify the effects of bed slope and relative submergence on incipient motion of sediment under decelerating flows. Experiments were conducted in an experimental tilting-flume of $8 \mathrm{~m}$ long $0.4 \mathrm{~m}$ wide and $0.6 \mathrm{~m}$ deep with glass-walls. Three uniform sediments with median grain sizes of $0.95,1.8$ and $3.8 \mathrm{~mm}$ and three bed slopes of $0.0075,0.0125$ and 0.015 were used under decelerating flow. The main conclusion is that the Shields diagram, which is commonly used to evaluate the critical shear stress, is not suitable to predict the critical shear stress under decelerating flows.
\end{abstract}

Keywords: Fluvial hydraulics; Open channel flow; River beds; Sediment transport; Shear stress; Streamflow.

\section{INTRODUCTION}

Incipient motion of bed sediments is an important aspect in river engineering. For instance, to quantify aggradation and degradation in rivers, stable channel design, determine stability of riprap stones, it is required to have an adequate understanding of the incipient motion on sediment particles (Dey, 2014). The Shields diagram is most commonly used to quantify the conditions for the incipient motion of bed sediments (Shields, 1936). The diagram is presented in terms of critical Shields parameter $\Theta_{c}$ as a function of critical shear Reynolds number $R_{*_{c}}\left(=u_{*_{c}} d_{50} / v\right.$, where $u_{*_{c}}$ is the critical shear velocity; $d_{50}$ is the median sediment size; and $v$ is the coefficient of kinematic viscosity of water). The critical Shields parameter $\Theta_{c}$ is given by

$\Theta_{c}\left(R_{*_{c}}\right)=\frac{\tau_{0 c}}{\Delta g d_{50}}$

where $\tau_{0 c}$ is the critical bed shear stress $\left(=\rho u_{*_{c}}^{2}\right) ; \rho$ is the mass density of water; $\Delta$ is the relative submerged density $(=s-1) ; s$ is the relative density $\left(=\rho / \rho_{s}\right)$; and $g$ is the gravitational acceleration. Shields prepared the diagram $\Theta_{c}\left(R_{*_{c}}\right)$ for the incipient motion of uniform sediments under uniform flow, that is the zero-pressure gradient flow, by using experimental data. The diagram has a wide coverage of applicability from hydraulically smooth to rough regime through an intermediate transitional regime. Deviations from the Shields diagram, as observed by several investigators (e.g. Buffington and Montgomery, 1997), were mainly associated with the uncertainties in the evaluation of the bed shear stress due to the bed slope, relative submergence and also the definition of the threshold conditions, as referred to by Kramer (1935) and Dey (2014).

A number of studies were carried out concerning the slope dependency of the critical Shields parameter in longitudinal and transverse slopes (Chiew and Parker, 1994; Dey, 2003a; Dey and Debnath, 2000; Lamb et al., 2008). Results of these experimental studies, in particular those performed on steep slopes close to the angles of repose of sediments, showed that the critical bed shear stress is not only a function of the grain Reynolds number, but also depends on the longitudinal bed slope. The results indicated that the critical bed shear stress decreases with an increase in bed slope. However, Shvidchenko and Pender (2000) have stated that in uniform flow with a given bed shear stress and sediment size, the increase in bed slope and the corresponding decrease in flow depth can result in a greater resistance to flow due to a lower flow velocity and sediment transport rate.

A number of researchers investigated the influence of nonuniform flow (nonzero-pressure gradient flow) on incipient motion of sediments. Afzalimehr et al. (2007) studied the influence of decelerating flow on incipient motion of gravel-bed and found that the Reynolds shear stress distribution takes a convex form over fixed and mobile beds. Due to this convex form, the critical Shields parameter for decelerating flow is less than that reported in the literature. Emadzadeh et al. (2010) estimated the effects of nonuniform flows on incipient motion. They found that the Reynolds normal stress is considerably greater than the Reynolds shear stress in all measured profiles, and the nonuniform flows along with bed slope variation are the key factors governing the incipient motion in sediments.

From the literature survey, it is revealed that the application of the Shields diagram may produce inconsistent results of the critical bed shear stress in the case of a nonuniform flow. Also, the interaction of bed slope and relative submergence in a decelerating flow needs to be investigated because a decelerating flow is frequently observed over bedforms. Therefore, the objective of the paper is to report the results of an experimental study to understand the effects of bed slope and relative submergence on incipient motion of sediment under decelerating flows.

\section{EXPERIMENTATION}

Experiments were conducted in a tilting-flume 8-m long, $0.4-\mathrm{m}$ wide and $0.6-\mathrm{m}$ deep with glass-walls at the Isfahan University of Technology, Iran. The flow depth was controlled by a tailgate at the end of the flume and was measured by a mobile limn-meter (a point gauge). The flow undulations in the inlet head-box were damped by using a grid structure to ensure a stabilized flow condition in the flume during the experiments. 
A decelerating flow condition in the flume was maintained by setting the flow depth to increase and the flow velocity to decrease with distance, aided by adjusting the tailgate and the bed slope. The slope of the flume was first set as horizontal and the depth of sediment varied along the flume to achieve different longitudinal bed slopes. Three uniform sediments with median grain sizes $d_{50}$ of $0.95,1.8$ and $3.8 \mathrm{~mm}$ were used (Fig. 2 ). In order to prevent local scour and to achieve a fully developed flow, an upstream reach of $4 \mathrm{~m}$ from the inlet of the flume was covered with gravel. A summary of the experimental data is furnished in Table 1. All the measurements were taken at the locations 5, 5.75 and $6.5 \mathrm{~m}$ from the flume inlet (see Fig. 1) to ensure a fully developed flow at the test locations and to have a flow unaffected by the tailgate. Chen and Chiew (2003) reported that the effect of the roughness height, bed shear stress, turbulent intensity and Reynolds shear stress distributions to a sudden change in the bed can be ignored approximately after a distance of 5 to 6 times the flow depth. Thus, it can be assumed that a change in the bed roughness at the end of the first $4 \mathrm{~m}$ would not have any effect on the measurements at the test sections at $5 \mathrm{~m}$ from the flume inlet or more.

Before starting the experiments, the sediment bed was screened and the flume was slowly filled with water from the downstream end so that the water depth was at least $0.1 \mathrm{~m}$ above the bed. The pump was then started and the flow rate was very gradually increased until incipient motion was observed at the $5 \mathrm{~m}$ test section. The weak movement criterion, as proposed by Kramer (1935), was used to identify the incipient motion condition in the experiments. Under this condition, a small number of sediment particles at isolated positions with countable amount were in motion.

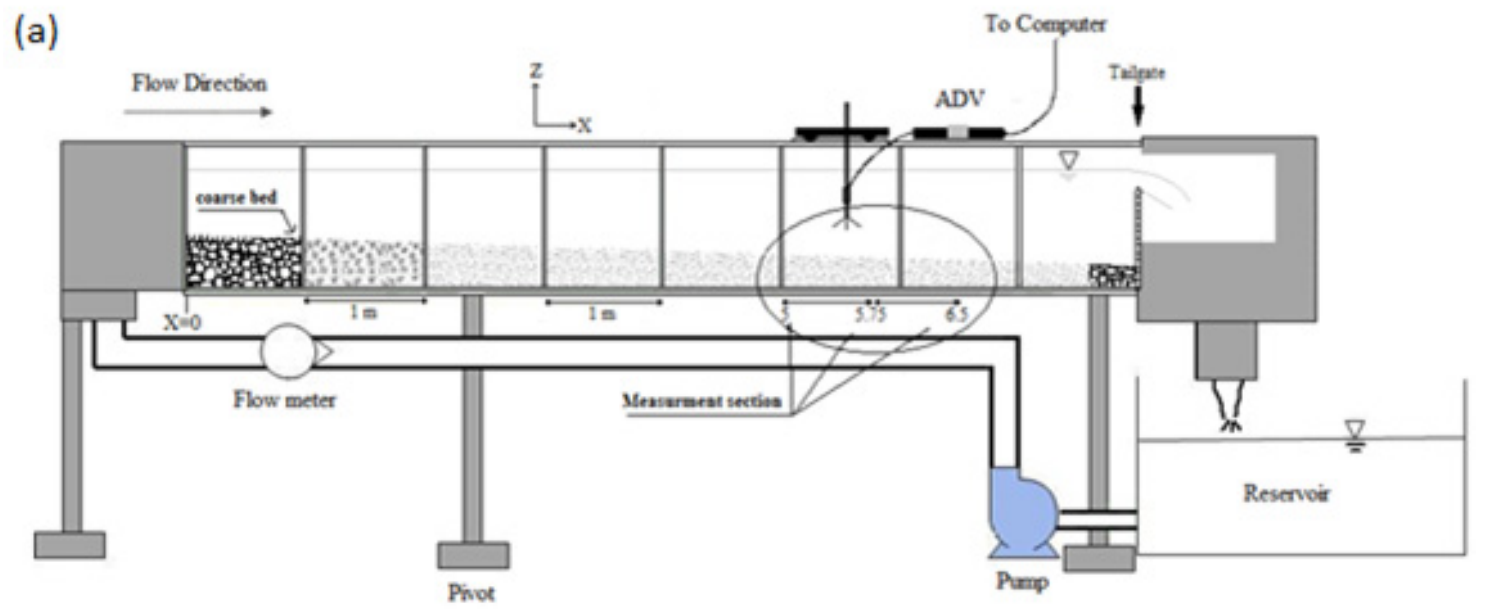

(b)

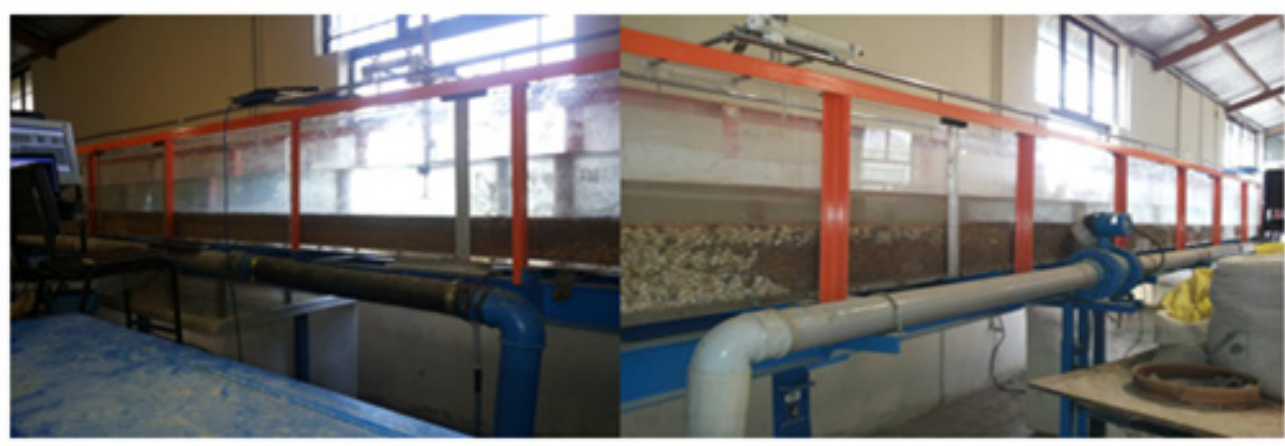

Fig. 1. Experimental set up: (a) a plan of flume set up; (b) flume set up.

Table 1. A summary of experimental data.

\begin{tabular}{lccccccccc}
\hline \multicolumn{1}{c}{ Run } & $\begin{array}{c}\mathrm{Q} \\
\left(\mathrm{m}^{3} / \mathrm{s}\right)\end{array}$ & $\begin{array}{c}h \\
(\mathrm{~cm})\end{array}$ & $h / \mathrm{d}_{50}$ & $\mathrm{Fr}$ & $\begin{array}{c}\mathrm{U} \\
(\mathrm{m} / \mathrm{s})\end{array}$ & $\operatorname{Re} \times 10^{5}$ & $\begin{array}{c}\mathrm{u}_{* \mathrm{*b}} \\
(\mathrm{m} / \mathrm{s})\end{array}$ & $\Theta_{c}$ & $R_{*}$ \\
\hline II-0.0125-ho 5.75 & 0.042 & 23.5 & 130.55 & 0.281 & 0.426 & 0.992 & 0.034 & 0.040 & 61.32 \\
II-0.015-ho 5.75 & 0.040 & 24.5 & 136.11 & 0.252 & 0.391 & 0.946 & 0.028 & 0.027 & 50.03 \\
II-.0075-ho 5.75 & 0.050 & 23.0 & 127.77 & 0.334 & 0.502 & 1.145 & 0.030 & 0.032 & 54.49 \\
I-0.0075-ho 5.75 & 0.033 & 23.0 & 242.10 & 0.176 & 0.265 & 0.604 & 0.015 & 0.008 & 14.35 \\
I-0.0125-ho 5.75 & 0.034 & 24.3 & 255.78 & 0.301 & 0.301 & 0.725 & 0.014 & 0.007 & 13.94 \\
I-0.015-ho 5.75 & 0.029 & 23.1 & 243.15 & 0.191 & 0.287 & 0.437 & 0.019 & 0.013 & 18.38 \\
III-0.0075-ho 5.75 & 0.042 & 20.7 & 54.47 & 0.337 & 0.481 & 0.986 & 0.034 & 0.039 & 126.85 \\
III-0.0125-ho 5.75 & 0.042 & 20.7 & 53.94 & 0.326 & 0.464 & 0.952 & 0.036 & 0.044 & 135.50 \\
III-0.015-ho 5.75 & 0.040 & 19.7 & 51.84 & 0.333 & 0.463 & 0.904 & 0.040 & 0.056 & 152.36 \\
\hline
\end{tabular}




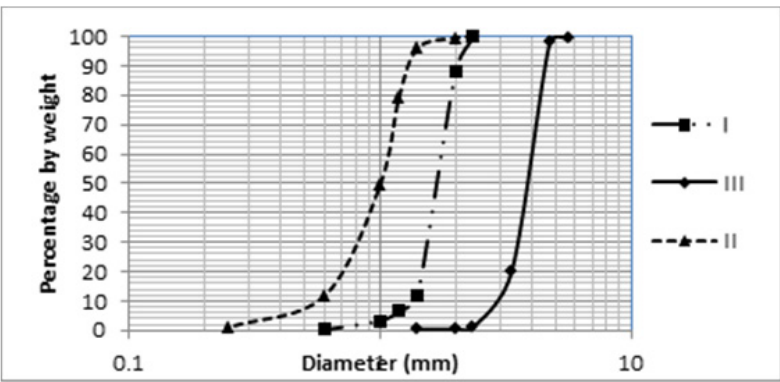

Fig. 2. Grain size distribution.

The instantaneous flow velocity was measured by an Acoustic Doppler Velocimeter (ADV) when the incipient motion was observed at all three locations 5, 5.75 and $6.5 \mathrm{~m}$. For each point, the sampling frequency was set at $200 \mathrm{~Hz}$ and the total sampling time was considered $2 \mathrm{~min}$. It is important to mention that the sample duration of 2 min was found to be adequate to determine time-averaged velocity and Reynolds stress. It was ascertained from the comparative results of the sample duration of $5 \mathrm{~min}$ near the bed. To remove possible aliasing effects, instantaneous velocity as a series of time was analyzed using WinADV software. The raw data were filtered by the phasespace threshold despiking filter (Nikora and Goring, 2000). During the experiments, adequate sound-to-noise ratio $(>14)$ and correlation coefficient $(>70 \%)$ were maintained. For each velocity profile, measurements of at least ten points were taken in the inner layer $(z / h \leq 0.2$, where $z$ is the vertical distance from the bed and $h$ is the flow depth) and another ten points were taken in the outer layer $(z / h>0.2)$. In summary, three slopes $(0.75,1.25$ and $1.5 \%)$ and three different sediment sizes were used in this study.

Table 1 shows the experimental data providing the designation of experimental runs in the first column having several parts to indicate the characteristics of each profile. In the first part, the letters represent the Roman numbers I, II and III indicating the bed sediment size, and the numbers 5, 5.75 and 6.5 correspond to the location of the measurements. The discharges ranging $0.029 \times 10^{-3}$ to $0.05 \times 10^{-3} \mathrm{~m}^{3} / \mathrm{s}$, Reynolds numbers $4.37 \times 10^{-4}$ to $1.145 \times 10^{-5}$ and Froude numbers 0.191 to 0.337 show that the flow condition was turbulent, subcritical in all the experiments. Although the aspect ratio that is the ratio of flume width to flow depth was less than 2, as the incipient motion is related to the bed shear stress or shear velocity, aspect ratio had a little role on affecting bed shear stress or shear velocity. Previously, Chiew and Parker (1994), Dey and Debnath (2000), Dey $(2003 \mathrm{a}, \mathrm{b})$ and others conducted experiments for studying incipient motion even in a condition of flow less than aspect ratio 2 .

\section{RESULTS \\ Shear velocity estimation}

Several methods are available to estimate shear velocity (the bed shear stress) of nonuniform flows, such as the Reynolds shear stress and log-law methods (Kironoto and Graf, 1995). In general, the log-law applies only the data of near-bed flow zone where a considerable uncertainty exists in the measurements, such as the determination of the reference bed level $(z=0)$, especially for sand and gravel-beds (Plott et al., 2013). The loglaw method assumes the flow to be in equilibrium implying that the flow conditions do not depend on the upstream conditions and the velocity and Reynolds shear stress distributions do not change along the flow direction (Graf and Altinakar 1998). Fig. 3 shows that the log-law fits well with data for different particle sizes and bed slopes. However, due to non-equilibrium flow conditions and variable reference bed level, the log-law method was not used to calculate the Shields parameter.
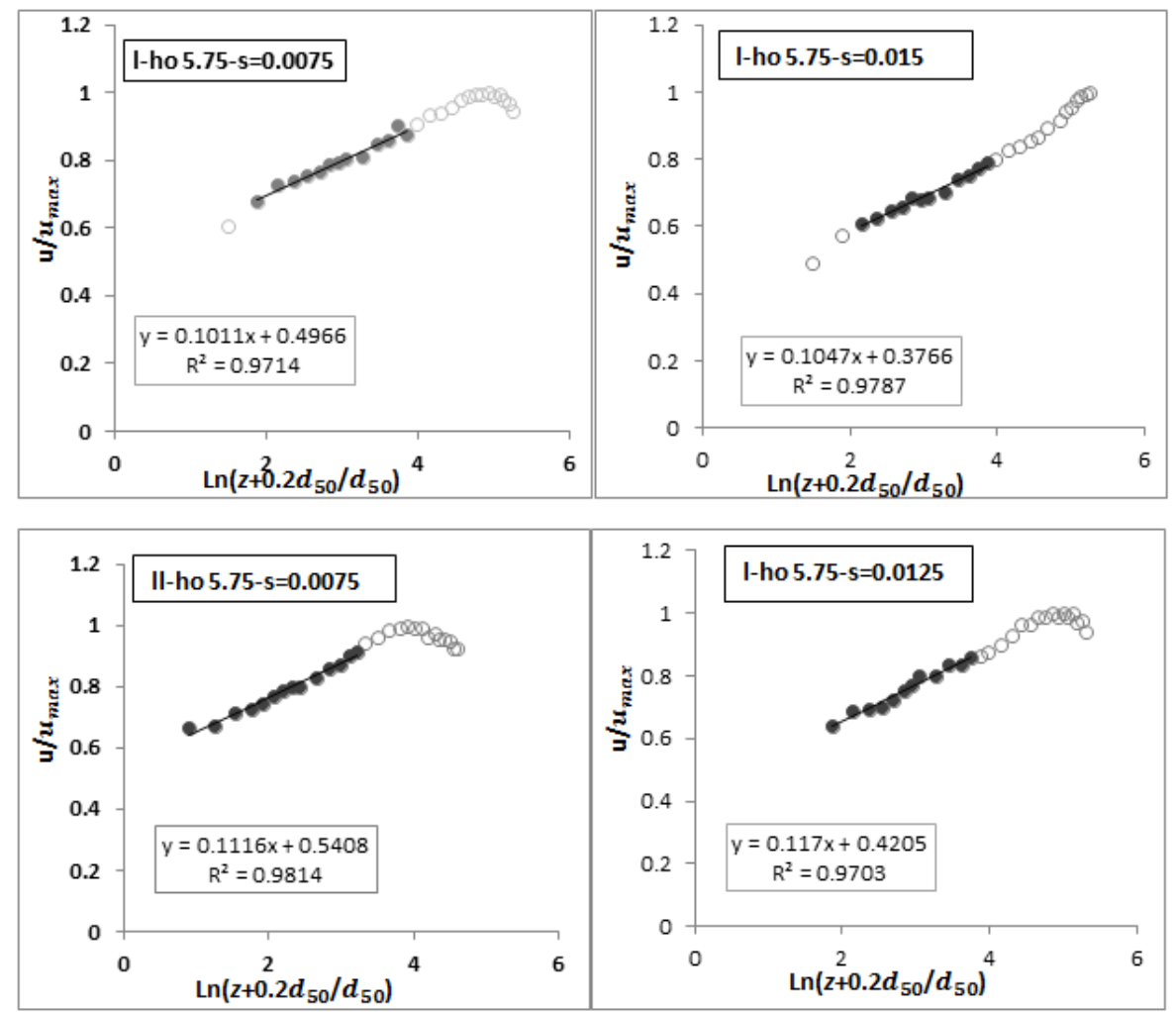

Fig. 3.1. Fit of the log law to the inner layer data. 

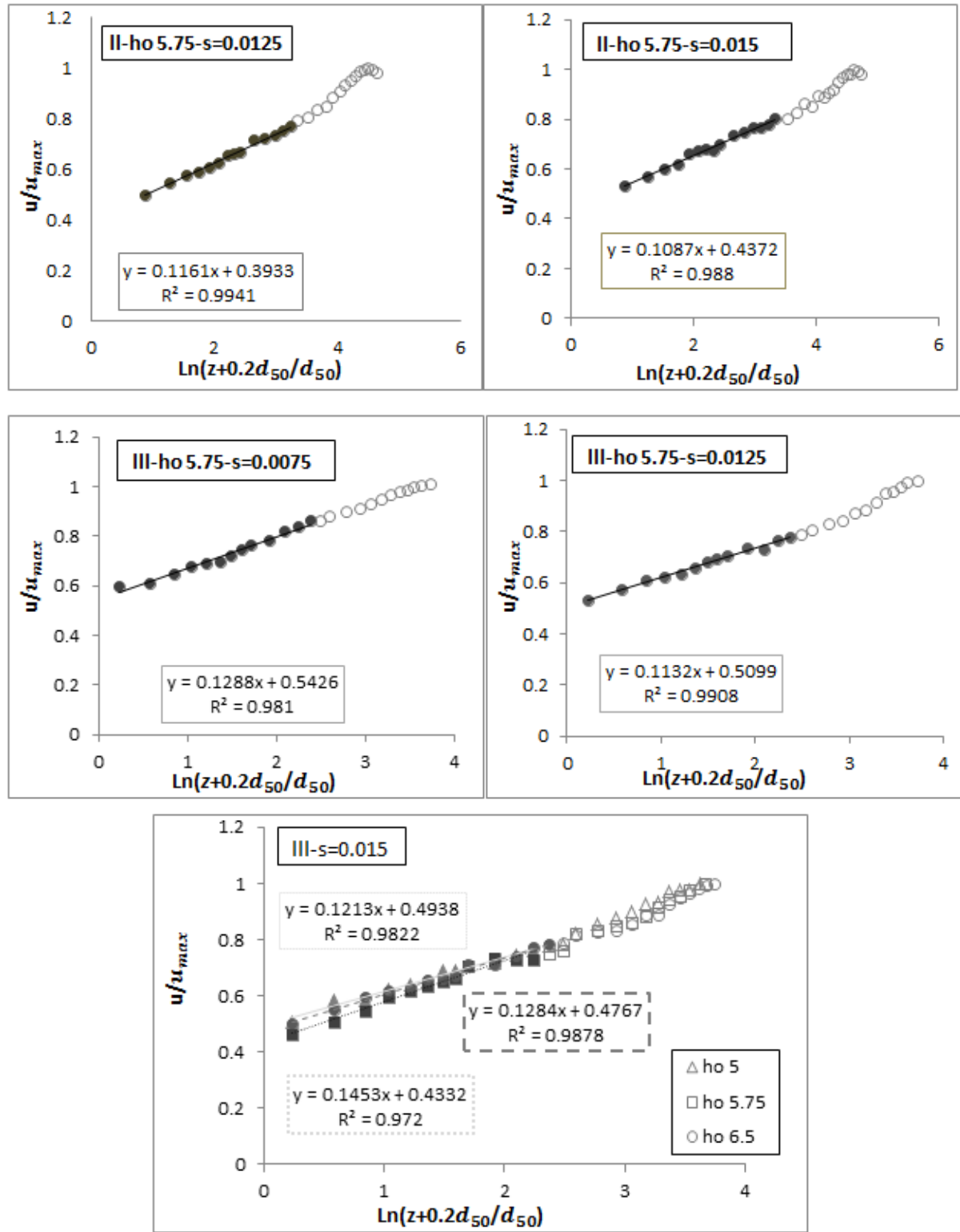

Fig. 3.2. Fit of the log law to the inner layer data (continue).

The shear velocity estimated using the Reynolds stress distribution is independent of velocity measurement and the assumption of the log-law in which the flow has to be in equilibrium (Barenblatt 1982 and Chen 1991). However, it is affected by the sediment size and the bed slope variation as is confirmed in Fig. 4. Furthermore, the fit of a second degree curve to the data or extension of a linear function to the bed is questionable. For example, in Fig. 4, the Reynolds shear stress (RSS) distributions near the bed are similar to the case I, while there is clear difference in RSS distributions for the case III. For these reasons, the RSS method was not considered to estimate shear velocity in this study. On the other hand, Fig. 5 reveals that under a mobile bed condition, the Reynolds normal stress values $\left(\sigma_{\mathrm{x}}\right)$ are much larger than the Reynolds shear stress values. However, the Reynolds normal stress distributions are affected by the sediment size and the bed slope near the bed and the free surface. This prevents the presentation of a general pattern of Reynolds normal stress distribution and to use it for evaluating shear velocity. Shear velocity $u *$ was also calculated using the boundary layer characteristics method (BLCM) for each velocity profile as follows (Afzalimehr and Anctil, 2000): $u_{*}=\frac{\left(\delta_{*}-\theta\right) u_{\max }}{4.4 \delta_{*}}$

where $\delta_{*}$ is the displacement thickness; $\theta$ is the momentum thickness; and $u_{\max }$ is maximum velocity observed in a velocity profile. The $\delta$ and $\theta$ are given by

$$
\begin{aligned}
& \delta_{*}=\int_{0}^{h}\left(1-\frac{u}{u_{\max }}\right) d z \\
& \theta=\int_{0}^{h} \frac{u}{u_{\max }}\left(1-\frac{u}{u_{\max }}\right) d z
\end{aligned}
$$

Since this method considers the effect of the shape of velocity profile and does not depend on flow development conditions, it was considered to calculate the shear velocity and then the Shields parameter in this study. Table 1 present the calculated values of shear velocity by this method as $u_{* \mathrm{~b} b}$. 

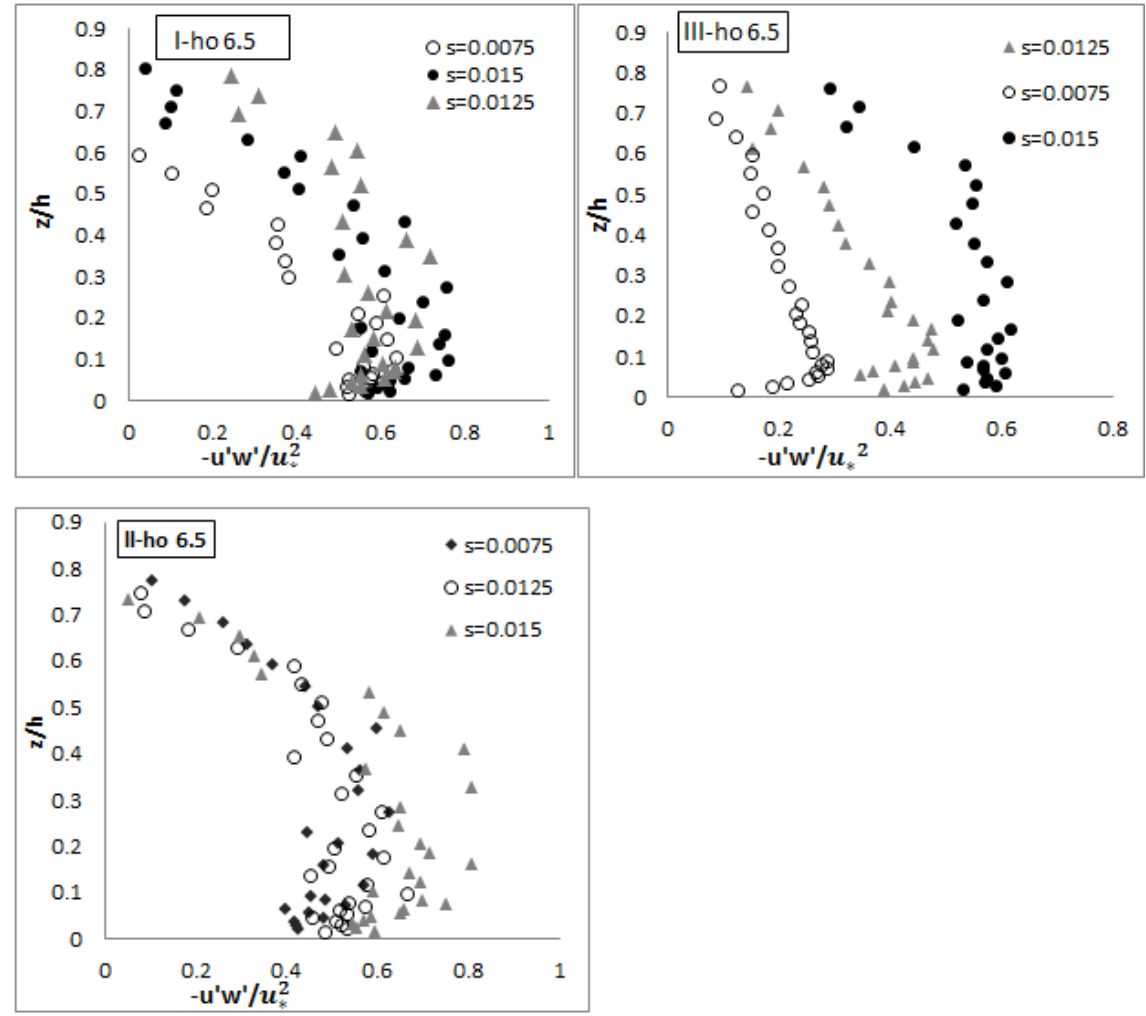

Fig. 4. Effect of bed-slope variation on the dimensionless shear stress distribution.
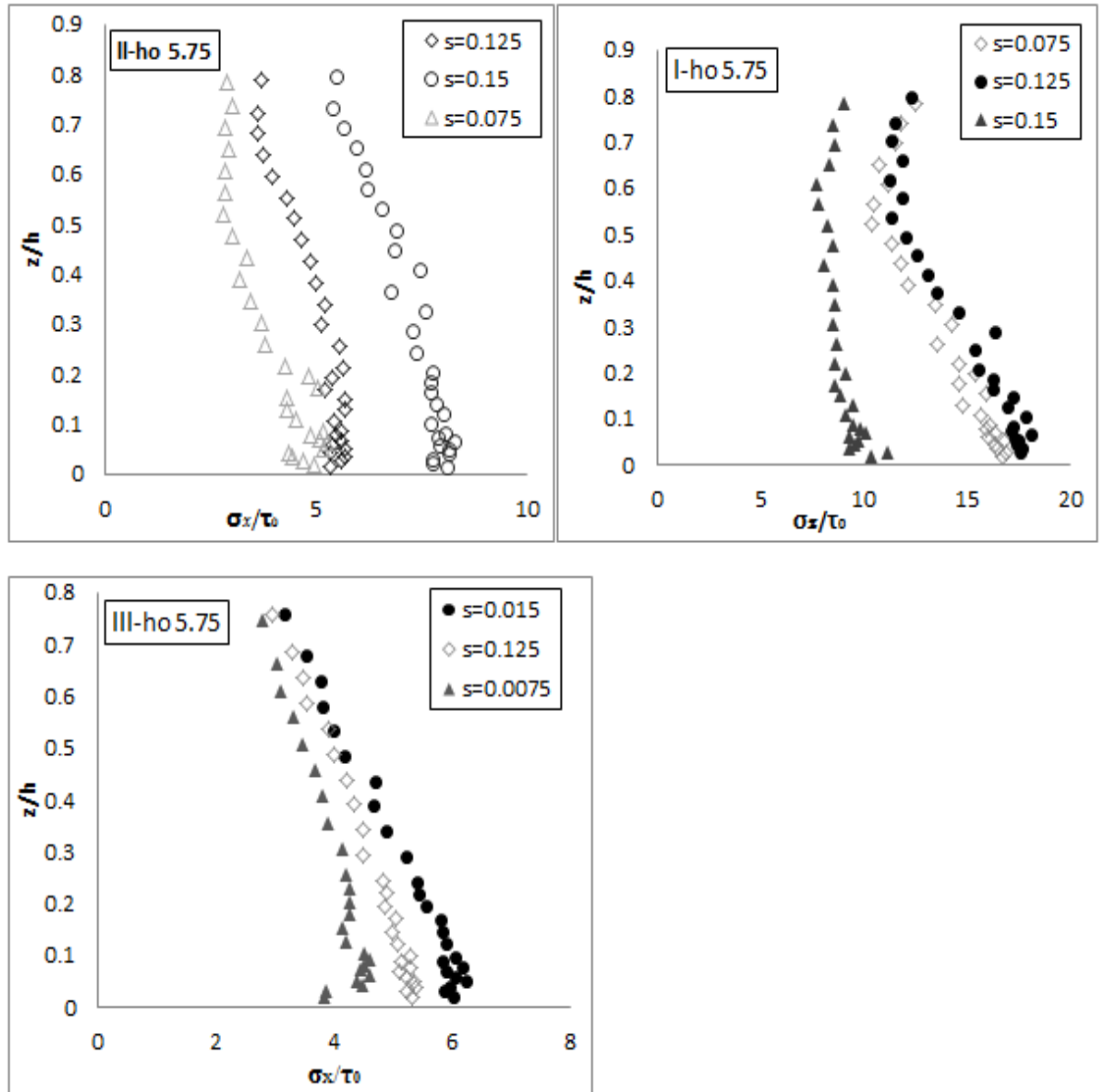

Fig. 5. Effect of bed-slope variation on normal stress distribution. 


\section{Effects of bed slope on sediment incipient motion}

To investigate the incipient motion of bed sediment under a decelerating flow, the effects of different bed slopes on the critical Shields parameter (critical Shields stress) $\Theta_{c}$ are analyzed. By varying the bed slope and tail water level, different decelerating flows were set in the laboratory flume. The variation of the bed slope not only causes a change in the pressure gradient, but also influences on sediment mobility, especially when the longitudinal bed slope is large. The longitudinal bed slope affects the incipient motion of bed sediment in two opposing ways, which may be categorized as pressure gradient and gravity effects. Both the factors are discussed in the following sections. The effects of the factors are clearly noticeable in the experimental results summarized in Table 1 and displayed in Fig. 6.

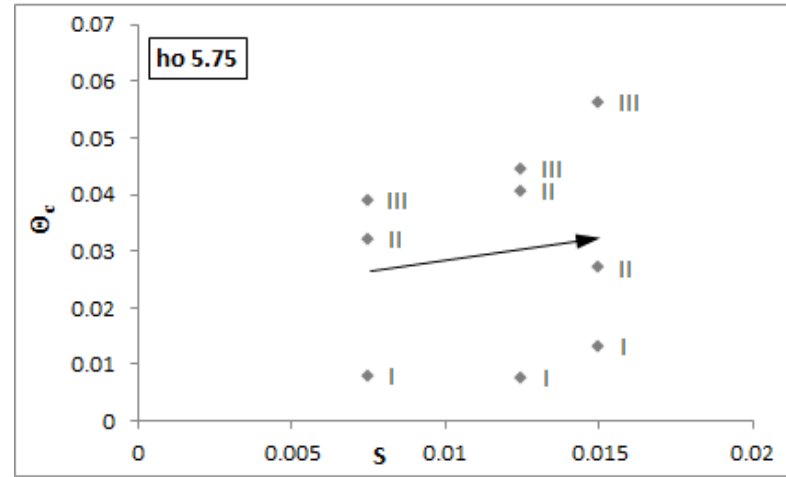

Fig. 6. Effect of bed slope variation on dimensionless Shield stress.

Fig. 6 displays a convex pattern for the curve of Shields parameter (dimensionless Shields stress) as a function of longitudinal bed slope. This pattern reveals that the pressure gradient effect is more important than the gravity effect. Under a zeropressure gradient flow, it is expected a linear relationship between the critical Shields parameter and bed slope, showing the peak of the bed stress at the bed. However, Fig. 4 shows that this is not true for a decelerating flow due the pressure gradient effect. Momentum equation states that at the bed $\partial p / \partial x=\partial \tau / \partial z$, where $p$ is the hydrostatic pressure; $x$ is the longitudinal distance; and $\tau$ is the Reynolds shear stress. For a zero-pressure gradient $\partial p / \partial x=0$, and thus $\tau=\rho g h S$, where $S$ is the longitudinal bed slope. However, for a decelerating flow, $\partial p / \partial x>0$, and thus near the bed $\partial \tau / \partial z>0$. Fig. 4 confirms such a convex distribution for different bed slopes and sediment sizes. Therefore, it is not only the longitudinal bed slope which affects the critical Shields parameter $\Theta_{c}$, but also the pressure gradient to affect the bed sediment to become less mobile, opposing to what is generally believed that sediment particles move easier under longitudinal slope. Fig. 6 displays that for a given sediment size, the required value of dimensionless Shields stress $\Theta_{c}$ to produces a given transport rate is not a linear function, but a convex one in which the maximum Shields stress occurs above the bed. This convex distribution confirms that the increase in the longitudinal pressure gradient near channel bed causes the decrease in the vertical shear stress, showing a convex pattern for adverse pressure gradient flows (decelerating flows).

\section{Effects of relative submergence on sediment incipient motion}

Fig.7 shows the relationship between the critical Shields parameter $\Theta_{c}$ and relative submergence $h / d_{50}$. Based on the classic interpretation of the Shields diagram for the transitional and rough-turbulent flows, the critical Shields parameter $\Theta_{c}$ decreases as the relative submergence $h / d_{50}$ increases. For a given bed shear stress and sediment size, the increase in bed slope and decrease in relative submergence cause a greater resistance to flow, and consequently, the flow velocity and the sediment transport rate reduce. As a result, for a steeper slope, a higher value of bed shear stress is required to produce a given sediment transport rate. However, based on Fig. 8, the relative submergence $h / d_{50}$ does not play a dominant role on the incipient motion, because for the fixed value of $h / d_{50}$, the critical Shields parameter is observed over or below the Shields curve. Based on traditional interpretation of the Shields diagram, no sediment motion is possible for the plots below the Shields curve, while the sediment motion is feasible for such plots under a decelerating flow. This reveals the Shields diagram cannot predict the critical conditions for incipient motion when the pressure gradient is prevalent.

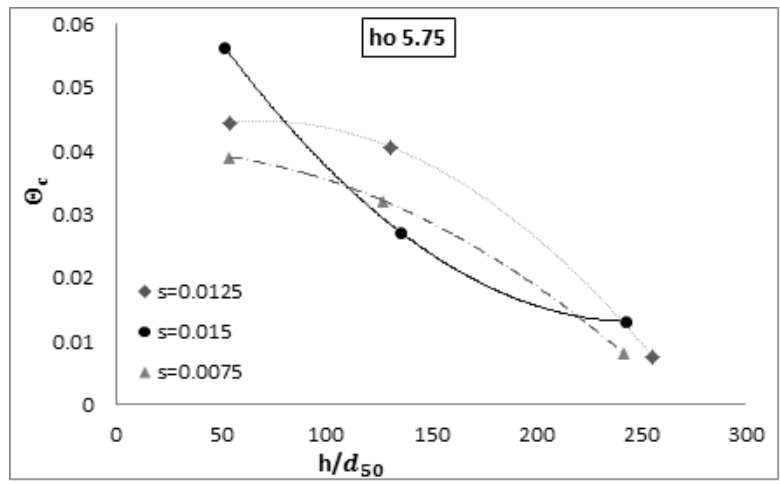

Fig. 7. Variation of dimensionless Shield stress with relative submergence.

It is possible that for very steep slope approaching the angle of repose of bed sediment, the interaction of relative submergence and bed slope play an indispensable role on incipient motion which was considered by Luque and van Beek (1976), and Chiew and Parker (1994). However, it is beyond the scope of the present study. For the comparison of the results, data from other available studies (Afzalimehr et al., 2007; Emadzadeh et al., 2010) as well as threshold curve obtained by Rouse (1949) are displayed on Fig. 8.

The Shields diagram shows that the critical Shields stress is constant at large grain Reynolds numbers. Trial and error calculations must be made for determining the critical flow value in this case. On the other hand, the collected data were used based on the modification of the proposed diagram by Yalin (1971). In Fig. 9, the critical Shields stress is presented using the bed slope and particle parameter $d_{*}=d_{50}\left(g \Delta / v^{2}\right)^{1 / 3}$. The advantage of Fig. 9 is that $d_{*}$ can be calculated from the known fluid and sediment properties; and thus the critical Shields parameter for a given bed slope can be determined directly without a trial and error process.

It is considered in Fig. 9 that for a given bed slope, the critical Shields parameter $\left(\Theta_{c}\right)$ cannot be evaluated by the Shields curve because in some cases the incipient motion occurs, but $\Theta_{c}$ is under the Shields curve. Although it is supposed that no mo- 


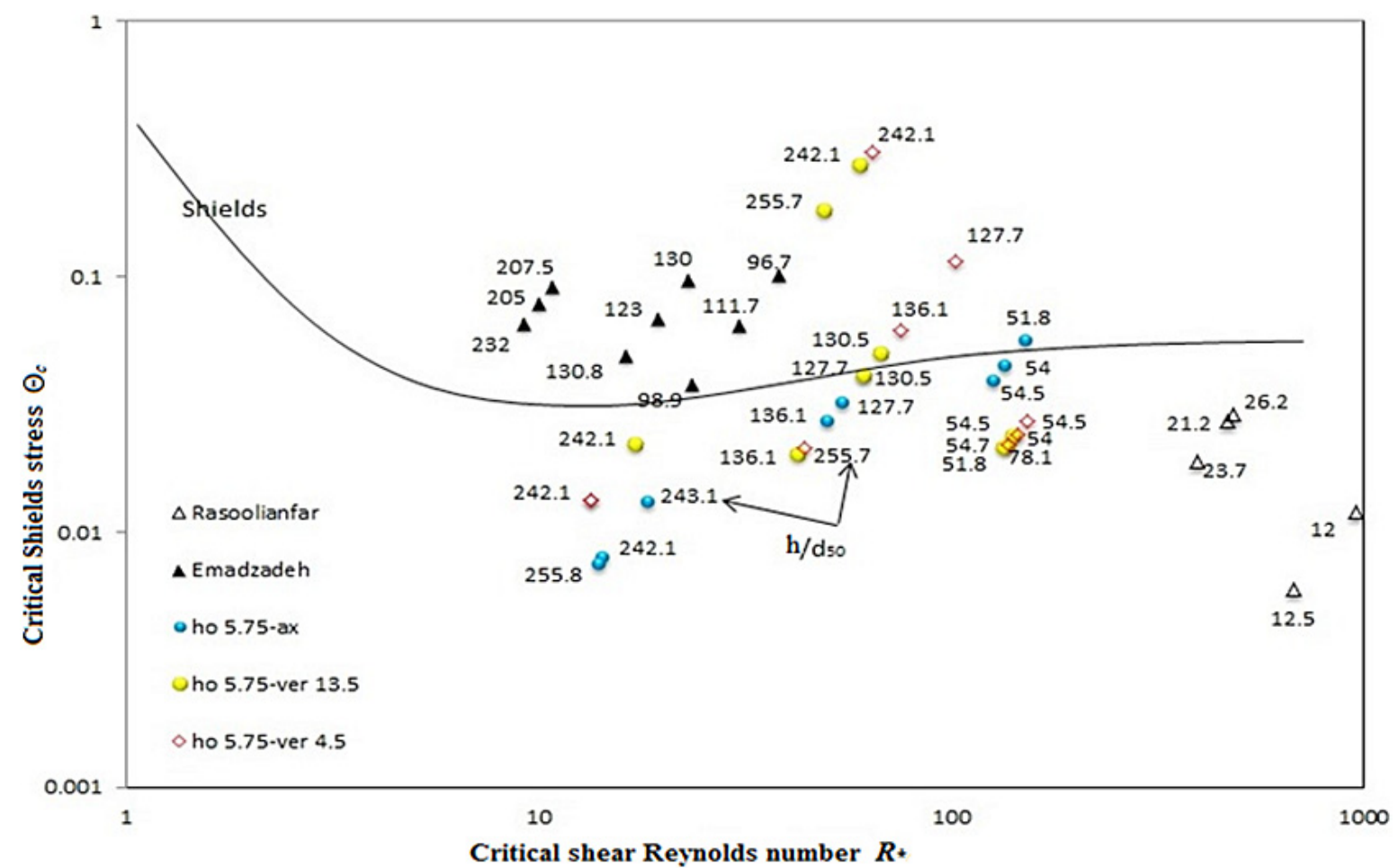

Fig. 8. Dimensionless Shields stress versus grain particle Reynolds number.

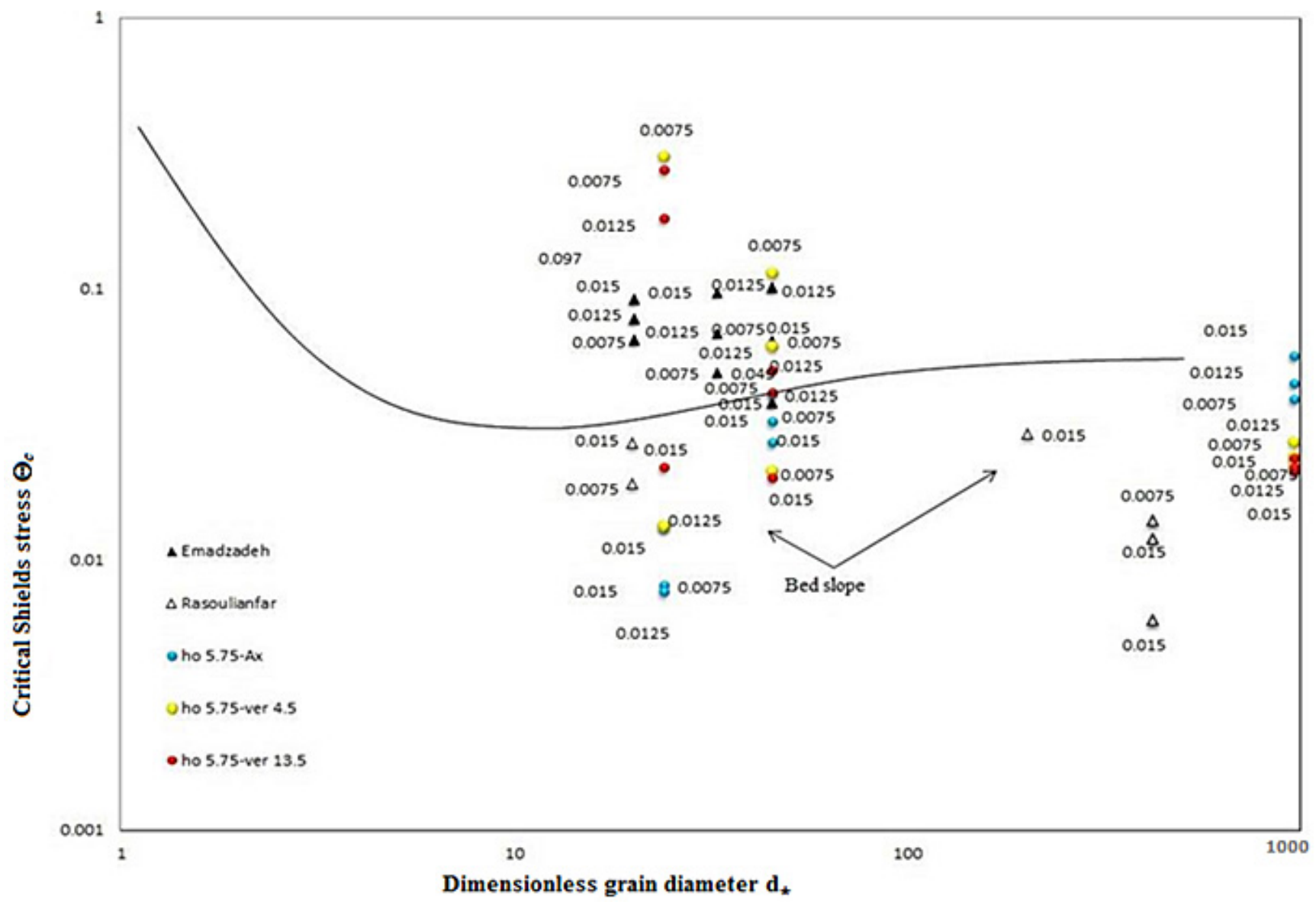

Fig. 9. Dimensionless Shields stress versus dimensionless grain diameter.

tion is possible for the points below the curve, the present results reveal that all data in Fig. 9 above or below the Shields curve are in motion. This requires further consideration of the effects of pressure gradient on the incipient motion of sediment and the proposal of a new diagram to evaluate the critical bed shear stress.

Figs. 8 and 9 show the values of critical Shields stress calculated at the distances of $4.5 \mathrm{~cm}$ and $13.5 \mathrm{~cm}$ from the vertical 
walls of flume. No specific pattern was observed at these distances when they were compared with the central axis values, showing independency of the critical Shields stress values from the vertical wall distance.

\section{CONCLUSIONS}

An understanding of incipient motion conditions is important in sediment transport studies for evaluating the bed load transport rate because most of bed load equations are based on the critical Shields stress. The results of an experimental study to quantify the effects of bed slope and relative submergence on incipient motion of sediment under decelerating flows are presented. Three uniform sediments with median grain sizes of $0.95,1.8$ and $3.8 \mathrm{~mm}$ and three bed slopes of $0.0075,0.0125$ and 0.015 were investigated under decelerating flow. The results of present study reveal that the decelerating flow plays significant role on the incipient motion of sediment. The convex distribution of critical Shields stress versus the bed slope reveals the effect of decelerating flow at the incipient motion. It is finally concluded that the Shields diagram that is widely used to evaluate the critical shear stress is unsuitable to predict the critical shear stress under decelerating flows because in some cases the incipient motion occurs, but the critical Shields stress is under the curve.

\section{REFERENCES}

Afzalimehr, H., Anctil, F., 2000. Accelerating shear velocity in gravel channel. J. Hydrol. Sci., 45, 113-24.

Afzalimehr, H., Dey, S., Rasoulianfar, P., 2007. Influence of decelerating flow on incipient motion of gravel-bed streams. Sadhana., 32, 545-559.

Barenblatt, G.I., 1982. Similarity self-similarity and intermediate asymptotics. Kluwer Academic, Dordrecht, The Netherlands.

Buffington, J.M., Montgomery, D.R., 1997. A systematic analysis of eight decades of incipient motion studies, with special reference to gravel-bedded rivers. Water Resour. Res., 33, 1993-2029.

Chen, C.L., 1991. Unified theory on power laws for flow resistance. J. Hydraul. Eng., 117, 371-389.

Chen, X., Chiew, Y.M., 2003. Response of velocity and turbulence to sudden change of bed roughness in open-channel flow. J. Hydraul. Eng., 120, 35-43.

Chiew, YM., Parker, G., 1994. Incipient sediment motion on non-horizontal slopes. J. Hydraul. Res., 32, 649-660.

Dey, S., 2003a. Threshold of sediment motion on combined transverse and longitudinal sloping beds. J. Hydraul. Res., $141,405-415$.

Dey, S., 2003b. Incipient motion of bivalve shells on sand beds under flowing water. J. Eng. Mech., 129, 232-240.

Dey, S., 2014. Fluvial hydrodynamics: Hydrodynamic and sediment transport phenomena. Springer-Verlag. Berlin.

Dey, S., Debnath, K., 2000. Influence of stream-wise bed slope on sediment threshold under stream flow. J. Irrig. Drain. Eng., 126, 255-263.

Egiazaroff, I.V., 1965. Calculation of non-uniform sediment concentrations. J. Hydraul. Div., 91, 225-247.

Emadzadeh, A., Chiew, Y.M., Afzalimehr, H., 2010. Effect of accelerating and decelerating flows on incipient motion in sand bed streams. Adv. Water Resour., 33, 1094-1104.

Graf W.H, Altinakar M.S., 1998. Fluvial Hydraulics, Flow and Transport Processes in Channel of Simple Geometry. John Wiley and Sons, New York.
Kironoto, B.A., Graf, W.H., 1995. Turbulence characteristics in rough non-uniform open channel flow. Proc. Inst. Civil Eng., Water, Maritime and Energy, 112, 336-348.

Kramer, H., 1935. Sand mixtures and sand movement in fluvial models. Trans. Am. Soc. Civil Eng., 100, 798-878.

Lamb, M.P., Dietrich, W.E., Venditti, J.G., 2008. Is the critical shields stress for incipient sediment motion dependent on channel-bed slope? J. Geophys. Res., Earth Surface, 113, F02008, doi:10.1029/2007JF000831.

Luque, R.F., Beek, R., 1976. Erosion and transport of bedload sediment. J. Hydraul. Res., 14, 127-144.

Nikora, V., Goring, D., 2000. Flow turbulence over fixed and weakly mobile gravel beds. J. Hydraul. Eng., 126, 679-690.

Plott, J.R., Diplas, P., Kozarek, J., Dancey, C.L., Hill, C., Sotiropoulos, F., 2013. A generalized log law formulation for a wide range of boundary roughness typically encountered in natural streams. J. Geophys. Res., Earth Surface, 118, 1419-1431, doi: 10.1002/jgrf.20104.

Raupach, M.R., Antonia, R.A., Rajagopalan, S., 1991. Roughwall turbulent boundary layers. Appl. Mech. Rev., 44, 1-25.

Rouse, H., 1949. Engineering Hydraulics. Wiley, New York.

Shields, A.F., 1936. Application of similarity principles and turbulence research to bed-load movement. Mitteilungen der Preussischen Versuchsanstalt für Wasserbau und Schiffbau, Berlin, Germany, 26, 5-24

Shvidchenko, A.B., Pender, G., 2000. Flume study of the effect of relative depth on the incipient motion of coarse uniform sediments. Water Resour. Res., 36, 619-628.

Yalin, M.S., 1971. Theory of Hydraulic Models. Macmillan, London.

\section{NOMENCLATURE}

$d_{50}$ median grain size

$d_{*} \quad$ particle parameter $d_{*}=d_{50}\left(g \Delta / v^{2}\right)^{1 / 3}$

$h \quad$ water depth

Fr Froude number, $\mathrm{Fr}=\mathrm{U} / \sqrt{g h}$

g gravitational accelerating

$\mathrm{P}$ pressure

Q flow discharge

$\operatorname{Re}$ Reynolds number. $\operatorname{Re}=U h / v$

$R * \quad$ particle Reynolds number, $R *=u_{*}{ }_{c} d_{50} / v$

$s \quad$ relative density, $s=\rho_{s} / \rho$

$S$ bed slope

$\mathrm{u}$ mean point velocity

$\mathrm{u}_{\max }$ maximum flow velocity

$\mathrm{U}$ cross-section average velocity, $\mathrm{U}=\mathrm{Q} / \mathrm{b} h$

$u_{*} \quad$ shear velocity

$u_{* b \mathrm{l}}$ shear velocity estimated by the boundary layer method

$z \quad$ distance from the bed

$\Delta$ relative submerged density, $\Delta=s-1$

$\Theta_{c} \quad$ Critical Shields stress, $\Theta_{c}=\tau_{0} /\left(\rho_{\mathrm{s}}-\rho\right) \operatorname{gd}_{50}$

$v$ coefficient of kinematic viscosity of water

$\rho \quad$ fluid density

$\rho_{s} \quad$ sediment density

$\sigma_{\mathrm{x}}$ Reynolds normal stress in longitudinal direction

$\tau \quad$ Reynolds shear stress

$\tau_{0 c} \quad$ critical bed shear stress, $\tau_{0 c}=\rho u_{*_{c}}^{2}$

Received 29 January 2015 Accepted 31 July 2015 